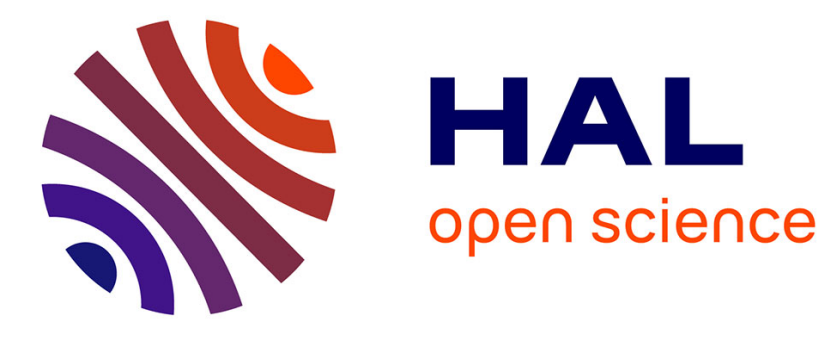

\title{
Acoustic performance analysis of bionic coupling multi-layer structure
}

Y.H. Wang, C.C. Zhang, L.Q. Ren, Mohamed Ichchou, Marie-Annick Galland, Olivier Bareille

\section{- To cite this version:}

Y.H. Wang, C.C. Zhang, L.Q. Ren, Mohamed Ichchou, Marie-Annick Galland, et al.. Acoustic performance analysis of bionic coupling multi-layer structure. Applied Mechanics and Materials, 2014, 461, pp.22-30. 10.4028/www.scientific.net/AMM.461.22 . hal-00971622

\section{HAL Id: hal-00971622 \\ https://hal.science/hal-00971622}

Submitted on 3 Apr 2014

HAL is a multi-disciplinary open access archive for the deposit and dissemination of scientific research documents, whether they are published or not. The documents may come from teaching and research institutions in France or abroad, or from public or private research centers.
L'archive ouverte pluridisciplinaire HAL, est destinée au dépôt et à la diffusion de documents scientifiques de niveau recherche, publiés ou non, émanant des établissements d'enseignement et de recherche français ou étrangers, des laboratoires publics ou privés. 


\title{
Acoustic Performance Analysis of Bionic Coupling Multi-layer Structure
}

\author{
Yonghua Wang ${ }^{1,2, a}$, Chengchun Zhang ${ }^{1, b}$, Luquan Ren ${ }^{1, \mathrm{c}}$, \\ Mohamed Ichchou ${ }^{2}$, Marie-Annick Galland ${ }^{3}$, Olivier Bareille ${ }^{2}$
}

1. Key Laboratory of Bionic Engineering (Ministry of Education), Jilin University, Changchun 130022, P. R. China

2. Laboratory of Tribology and System Dynamics, Ecole Centrale de Lyon, Ecully 69134, France

3. Laboratory of Fluid Mechanics and Acoustics, Ecole Centrale de Lyon, Ecully 69131, France

a Yonghua.Wang@ec-lyon.fr, ${ }^{\mathrm{b}}$ jluzcc@jlu.edu.cn, ${ }^{\mathrm{c}}$ lqren@jlu.edu.cn

Corresponding author: Chengchun Zhang E-mail: jluzcc@jlu.edu.cn full telephone: +8613504338189

\section{Abstract}

The interest of this paper lies in the proposition of using bionic method to develop a new sound absorption structure. Inspired by the coupling absorption structure of the skin and feather of a typical silent flying bird - owl, a bionic coupling multi-layer structure model is developed, which is composed of a micro-silt plate, porous fibrous material and a flexible micro-perforated membrane backed with airspace. The impedance transfer method is applied to calculate the absorption coefficients and analyze the influences of different parameters of each layer on absorption coefficients of this model. Based on numerical simulations, the effectiveness of this proposed model is tested. The average absorption coefficient reaches 0.85 within the frequency band of $200 \mathrm{~Hz}$ to $2000 \mathrm{~Hz}$. The significant improvement of absorption coefficients can be mainly due to the Helmholtz effects of the micro-silt plate and flexible micro-perforated membrane, and the combination with porous materials can lead to even better absorption performance in broadband.

Keywords: Biomimetic method; Multi-layer acoustic structure; Impedance transfer method; Absorption coefficients

\section{Introduction}

In recent years, noise control has attracted much attention for improving living environments. Multi-layer acoustic absorbers composed of perforated plates, airspaces and porous materials are commonly applied to absorb broadband noise. However, the acoustic absorption of these multi-layer acoustic absorbers is mainly dependent on their fabrication. In this paper, a new absorption structure is developed through biomimetic method, and the factors that have significant influence on the acoustic absorption performance are analyzed.

Biology has perfected its designs and formed many fruitful abilities through billions of years' evolution. Efficient and reliable technologies and achievements can be developed by adopting the features of natural creations ${ }^{[1-5]}$. The owl, as observed today, has passed through series of evolution for over 12 million years. It is suggested that the owl has developed its strategy of a silent predator based on various characteristics of its body surface. At present, in the field of bionics, investigations on the noise reduction characteristics of owl body surface are mainly focused on its morphological features. Through comparative experiments on morphological characteristics of owl's wing surface, Graham ${ }^{[6]}$ revealed that its special wing feathers had a significant impact on noise reduction capacity. Based on pneumatic noise test during the predation process of striped owl, Kroeger et al. ${ }^{[7]}$ found that the primary feather edge was indented, which was conducive to noise suppression and even influenced its physical trajectory. Through long-term observation and experiments, Lilley et 
al. ${ }^{[8]}$ proposed following tentative but plausible reasons for the reduction and suppression of noise: (1) leading edge of primary feathers in the form of a comb, (2) trailing edge feathers in the form of a fringe, and (3) fluffy down on the wings, abdomen, legs and tarsus. In 2004, Lilley ${ }^{[9]}$ attempted to optimize the take-off and landing of quiet commercial passenger transport according to the noise reduction characteristics of owl body surface and obtained satisfactory results. Ren et al. ${ }^{[10,11]}$ considered that the skin and feather of owl chest and abdominal may also play an important role on its silent flight. It was concluded that the noise suppression of the owl chest and abdominal was due to the synergy effect of material, skin structure and feather shape etc., and further named as biological coupling. Inspired by this fact, a bionic coupling multi-layer structure is established in this article according to the bionic analogy principle.

Davern ${ }^{[12]}$ presented an experimental study on a three-layer assembly which contained perforated plate, porous material and airspace. Dunnand and Davern ${ }^{[13]}$ proposed an analytical analysis for the flat-walled anechoic lining composed of outer, middle and inner layer porous materials. Jinkyo et al. ${ }^{[14]}$ further studied the assembly with two layers of perforated plates backed with airspaces by an equivalent electrical circuit method (EECM). Chen et al. ${ }^{[15]}$ applied finite element method (FEM) to analyze the acoustic absorption of porous materials with different surface shapes and perforated plates. Lin et al. ${ }^{[16]}$ provided a detailed investigation of the impact of porous materials with different thickness and configuration on the perforated plate. Lee et al. ${ }^{[17]}$ estimated the absorption performance of multiple layer perforated plate systems by transfer matrix method (TMM). Lee and Chen ${ }^{[18]}$ proposed acoustic transmission analysis method to analyze the absorption of multi-layer absorber, which was subsequently developed into the impedance transfer method (ITM). Zhao et al. ${ }^{[19]}$ compared EECM, ITM and TMM, and proved that ITM and TMM were essentially the same and more accurate than EECM. Accordingly, ITM is selected among all the methods for the analyses in this study.

\section{$[\ldots]$}

\section{Conclusions}

In this study, a bionic coupling multi-layer structure is developed based on the biomimetic method. The absorption coefficients and their influence factors of each layer are investigated by impedance transfer method. The bionic model shows excellent absorption performance. Its average absorption coefficient is found to be 0.778 within the frequency band of 0 to $2000 \mathrm{~Hz}$ while 0.85 from $200 \mathrm{~Hz}$ to $2000 \mathrm{~Hz}$. The optimal parameters are determined as $t_{1}=1 \mathrm{~mm}, d_{1}=0.5$ $\mathrm{mm}, p_{1}=15 \%, t_{2}=0.1 \mathrm{~mm}, d_{2}=0.05 \mathrm{~mm}, p_{2}=1 \%, D_{1}=20 \mathrm{~mm}, \sigma=20000 \mathrm{Ns} / \mathrm{m}^{4}, D_{2}=30 \mathrm{~mm}$. The significant improvement of absorption coefficients at low frequencies can be contributed to the Helmholtz effects of the micro-silt plate and flexible micro-perforated membrane, and the combination with porous materials, which leads to even better absorption performance in broadband. The study emphasizes that further investigations on the bionic coupling multi-layer structure can provide better absorbing system for practical applications.

\section{Acknowledgments}

All support is greatly acknowledged and appreciated, especially the constructive discussion and criticism from colleagues. Thanks are due to the Joint Funds of the National Natural Science Foundation of China (Grant No. U1134109), the Specialized Research Fund for the Doctoral Program of Higher Education of China (Grant No. 
and 51206058), for allowing to undertake the project and the financial support extended.

\section{References}

[1] Xue C Y, Chen S, Zhang W D, Zhang B Z, Zhang G J, Qiao H. Design, fabrication, and preliminary characterization of a novel mems bionic vector hydrophone. Microelectronics Journal, 2007, 38, 1021-1026.

[2] Han Z W, Niu S C, Shang C H, Liu Z N, Ren L Q. Light trapping structures in wing scales of butterfly trogonoptera brookiana. Nanoscale, 2012, 4, 2879-2883.

[3] Ren L Q, Tong J, Li J Q, Chen B C. Swsoil and water: Soil adhesion and biomimetics of soil-engaging components: a review. Journal of Agricultural Engineering Research, 2001, 79, 239-263.

[4] Sun T L, Feng L, Gao X F, Jiang L. Bioinspired surfaces with special wettability. Accounts of Chemical Research, $2005,38,644-652$.

[5] Feng L, Li H S, Li Y S, Li H J, Zhang L J, Zhai J. Superhydrophobic surfaces: From natural to artificial. Advanced materials, 2002, 14, 1857-1860.

[6] Graham R R. The silent flight of owls. The Journal of the Royal Aeronautical Society, 1934, 38, 837-843.

[7] Kroeger R A, Grushka H D, Helvey T C. Low Speed Aero-Dynamics for Ultra-Quiet Flight, Technical Report AFFDL-TR-71-75, Air Force Flight Dynamics Lab, Wright-Patterson Air Force Base, Ohio, USA, 1971.

[8] Lilley G M. A study of the silent flight of the owl. AIAA Paper, 1998, 2004-2186.

[9] Lilley G M. A quest for quiet commercial passenger transport aircraft for take-off and landing. AIAA Paper, 2004, 2922.

[10] Sun S M, Ren L Q, Xun C Y. Research on coupling sound absorption property of owl skin and feather. Noise and Vibration Control, 2008, 6, 119-123. (in Chinese)

[11] Liu T S, Kuykendoll K, Rhew R, Jones S. Avian wings. AIAA Paper, 2004, AIAA-2004-2186.

[12] Davern W A. Perforated facings backed with porous materials as sound absorbers- an experimental study. Applied Acoustics, 1977, 10, 85-112.

[13] Dunnand I P, Davern W A. Calculation of acoustic impedance of multilayer absorbers. Applied acoustics, 1986, 19, $321-334$.

[14] Jinkyo L, George W, Swenson J. Compact sound absorbers for low frequencies. Noise Control Eng J, 1992, 38, $109-117$.

[15] Chen W H, Lee F C, Chiang D M. On the acoustic absorption of porous materials with different surface shapes and perforated plates. Journal of sound and vibration, 2000, 237, 337-355.

[16] Lin L, Wang Z M, Jiang Z X. Effect of sound-absorbing material on a micro-perforated absorbing construction. ACTA acoustic, 2010, 4, 385-392. 
[17] Lee D H, Kwon Y P. Estimation of the absorption performance of multiple layer perforated panel systems by transfer matrix method. Journal of sound and vibration, 2004, 278, 847-860.

[18] Lee F C, Chen W H. Acoustic transmission analysis of multi-layer absorbers. Journal of Sound and Vibration, 2001, 248, 621-634.

[19] Zhao X D, Hu P, Sun P. The comparative analyses of the calculation methods for absorptivity of multilayer micro-perforated panel absorbers. Applied Acoustic, 2012, 3, 6. 